\title{
Kinetic Study of Subcritical Water Extraction of Garhohydrate from Microalgae Nannochloropsis sp.
}

\author{
Nur Baiti Listyaningrum ${ }^{1}$ \\ Muhammad Mufti Azis *,1 \\ Sarto ${ }^{1}$ \\ Anis Nurdhiani Rosdi ${ }^{2}$ \\ Mohd Razif Harun ${ }^{2}$ \\ ${ }^{1}$ Department of Chemical Engineering, Faculty of Engineering, Universitas Gadjah Mada, Sleman, \\ Yogyakarta, 55281, Indonesia \\ ${ }^{2}$ Department of Chemical and Environmental Engineering, Faculty of Engineering, Universiti Putra \\ Malaysia, Serdang, Selangor, 43400, Malaysia \\ "e-mail: muhammad.azis@ugm.ac.id
}

\section{Submitted 22 September $2020 \quad$ Revised 29 May $2021 \quad$ Accepted 02 June 2021}

\begin{abstract}
Microalgae contain a significant amount of carbohydrates that can be converted further to produce valuable compounds. To extract carbohydrates from microalgae, subcritical water extraction (SWE) is a viable and novel method. Compared to other existing chemical and biological extraction methods, SWE is more economical, effective, and efficient in terms of process conditions. This process uses high temperature and pressure of water at just below supercritical conditions to keep water at a liquid state. This study aims to investigate the factors that affect the extraction yield of carbohydrates from microalgae Nannochloropsis sp. using the SWE process. The extraction was carried out at a temperature of $160-320^{\circ} \mathrm{C}$, a duration of $5-25 \mathrm{~min}$, and microalgal biomass loading of $5-25 \% \mathrm{w} / \mathrm{v}$. The kinetics study was conducted in an extraction time of $5-25 \mathrm{~min}$ at $200{ }^{\circ} \mathrm{C}$ and $5 \%(\mathrm{w} / \mathrm{v})$ biomass loading. A simplified kinetic model based on a consecutive reaction was used to describe carbohydrate production and decomposition via SWE. It was found that the maximum yield of total carbohydrate was $18.04 \mathrm{~g} / 100 \mathrm{~g}$ which was obtained at $200{ }^{\circ} \mathrm{C}, 10 \mathrm{~min}$, and $5 \%(\mathrm{w} / \mathrm{v})$ microalgal biomass loading. The carbohydrate concentration was decreased as the temperature, extraction time and microalgal biomass loading increased. This result indicated that the SWE is a promising extraction method for carbohydrate recovery from microalgae, and the factors investigated here had a significant effect on the extraction process. The proposed kinetic model was also able to capture the experimental data well within the range of operating conditions studied in this work.
\end{abstract}

Keywords: Carbohydrate; Microalgae; Nannochloropsis sp.; Subcritical water extraction

\section{INTRODUCTION}

There has been a steady increase in the use of renewable natural sources for alternative energy. Microalgae biomass is one of the potential alternative sources due to its abundance, low cost, and natural presence. In addition, microalgae are fast-growing, do not require fertile land to grow, have high $\mathrm{CO}_{2}$ fixation efficiency, and contain high lipids (Zhao et al., 2013). Apart from lipids, microalgae also contain carbohydrates, proteins, and other various biocompounds 
12 Kinetic Study of Subscritical Water Extraction of Carbohydrate from Microalgae Nannochloropsis $\mathrm{sp}$.

(Yang et al., 2013), which can be further processed into bio-based products. Generally, carbohydrate is a useful ingredient to produces glucose via hydrolyzation. In addition, glucose is a vital substrate for heterotrophic microorganisms (such as yeast, bacteria, and fungi) to produce biofuels (Zhao et al., 2013).

Microalga biocompounds, especially carbohydrates are intracellularly produced and entrapped within the cells; thus microalgae cell walls must be ruptured completely to release those biocompounds (De Morais et al., 2015). One of the suitable technologies to optimize biocompounds release is subcritical water extraction (SWE). SWE is a rising technology for isolating compounds in biomass using water as the solvent at temperatures between $100-374$ ${ }^{\circ} \mathrm{C}$ and pressures of 5 - $22 \mathrm{MPa}$ (Yang et al., 2013, De Morais et al., 2015). Subcritical water facilitates structure degradation of microalgae cell walls and hydrogen bonds between lipid macromolecules and other organic macromolecules. Thus, subcritical water is feasibly employed to dissolve carbohydrates, ash, and other compounds with low calorific value (Huang et al., 2019).

Under subcritical conditions, water facilitates biomass extraction by having a specific properties such as low dielectric constants, weak hydrogen bonds, high diffusivity, and reactivity (Chan et al., 2017). Dielectric constant values can be controlled by changing temperature and pressure (Huang et al., 2019). This extraction will produce an aqueous phase and a solid phase (microalgae residue). This byproduct only becomes waste in the aqueous phase, whereas there are biochemical compounds such as carbohydrates and proteins contained in this phase (Awaluddin et al., 2016).
Other methods that can be done are microwave-assisted hydrothermal extraction (Tsubaki et al., 2017), ultrasound-assisted extraction (Zhao et al., 2013), hydrothermal liquefaction (Jin et al., 2017), steam explosions (Al hattab \& Ghaly, 2015), and acid hydrolysis (Vahabisani et al., 2015). However, those technologies also showed some limitations, such as long processing time, large amounts of toxic solvents, high energy, high cost of operation, and inefficient energy (Shahid et al., 2020).

The objective of the present work was to investigate the influence of process parameters (temperature, time, and microalgal biomass loading) for SWE of microalgal that obtain high carbohydrate production analyzed from the aqueous phase. In addition, a kinetic model to describe the SWE process was also proposed to improve our understanding of the SWE process.

\section{MATERIALS AND METHODS}

\section{Raw materials and chemical reagents}

Nannochloropsis sp., green algae with an average particulate size of $50-100 \mu \mathrm{m}$ was obtained from Xi'an Lyphar Biotech (China). In addition, glucose $\left(\mathrm{C}_{6} \mathrm{H}_{12} \mathrm{O}_{6}\right.$, R\&M Chemicals Ltd.), phenol (R\&M Chemicals Ltd.), and sulfuric acid $\left(\mathrm{H}_{2} \mathrm{SO}_{4}, \mathrm{R} \& \mathrm{M}\right.$ Chemicals Ltd., MW 98.079, 99\%) were obtained from the lab.

\section{Subcritical water extraction}

The Subcritical Water Extraction process was conducted in a batch system at different temperatures $\left(160-320{ }^{\circ} \mathrm{C}\right)$, time $(5-25$ min), and microalgal biomass loading (5 $25 \% \mathrm{w} / \mathrm{v}$ ) with a pressure of $0.6178-11.27$ MPa. The batch system contains a salt bath which must be preheated at a certain temperature for several minutes until the salt melts completely. Steam table was used as a 
reference to approximate the system pressure. The reaction cell was a stainlesssteel pipe (SUS 316) with an inner diameter of $7.5 \mathrm{~mm}$ and a length of $150 \mathrm{~mm}$. Microalgae at a certain loading concentration were mixed with $4 \mathrm{~mL}$ Milli-Q water and fed into a stainless-steel reactor with one side open. The reactor was purged with argon gas for 10 seconds to release trapped air inside the reactor.

The reactor was closed with Swagelok caps, then immersed into the salt bath that has reached the desired temperature for the specified time. The reactor was removed from the salt bath and left in water until cooled. The sample that has been extracted were centrifuged (KUBOTA 2420) at $4000 \mathrm{rpm}$ for 5 min. The supernatant and solid residue were separated by filtration. The general experimental setup diagram can be viewed in Figure 1.

\section{Determination method of carbohydrate}

The determination of total carbohydrate content was conducted by the phenolsulphuric acid method (Dubois et al., 1951). A set of dilution glucose standards $(0,10,25$, $50,200 \mathrm{mg} \mathrm{L}^{-1}$ ) was prepared. About $600 \mu \mathrm{L}$ of each standard was put in a glass tube followed by $600 \mu \mathrm{L}$ of $5 \%$ phenol and $3 \mathrm{~mL}$ sulphuric acid, then vortexed to ensure a homogenous solution.

The mixture was incubated under ambient conditions for $30 \mathrm{~min}$. Then, a UVVis spectrophotometer was used to determine the standard absorbance at a wavelength of $480 \mathrm{~nm}$. The results were used to create a calibration curve, and the equation was used to determine the carbohydrate contents of the sample after SWE. About $600 \mu \mathrm{L}$ of sample from SWE experiment was put in a glass tube followed by the addition of $600 \mu \mathrm{L}$ phenol (5\%) and 3
$\mathrm{mL}$ sulphuric acid. The mixture was wellstirred, incubated under ambient conditions for $30 \mathrm{~min}$, and further analyzed in UV-Vis spectrophotometer at the same wavelength of $480 \mathrm{~nm}$ to determine the carbohydrate content.

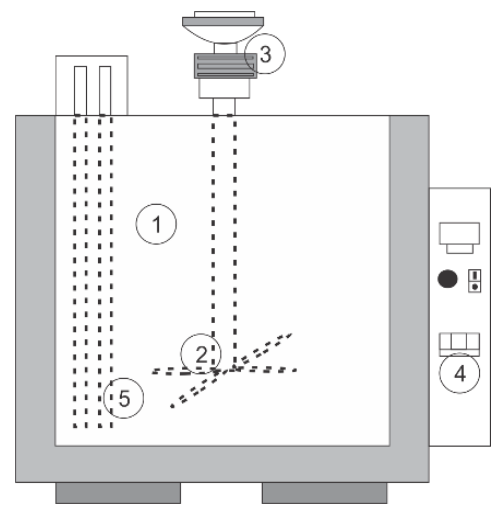

(a)

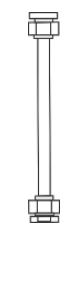

(b)
Fig. 1: SWE experimental setup a) (1) inner salt bath, (2) stirrer, (3) stirring motor, (4) operation panel, (5) heater, and b) reactor.

The carbohydrate yield was determined using Eq. (1).

$$
\begin{aligned}
\left(\begin{array}{c}
\text { carbohydrate } \\
\text { yield }
\end{array}\right)(\%) & =\left(\begin{array}{c}
\text { carbohydrate } \\
\text { concentration }
\end{array}\right)\left(m g \cdot \mathrm{mL}^{-1}\right) \\
& \times \frac{\text { g carbohydrate }}{1000 \mathrm{mg}} \\
& \times \frac{\text { total volume }(\mathrm{mL})}{\text { initial microalgae }(\mathrm{g})} \times 100
\end{aligned}
$$

\section{RESULTS AND DISCUSSION}

Three process parameters were investigated at five different levels to understand the impacts on microalgal subcritical water extraction. The results of carbohydrate extraction from SWE process are shown in Figures 2, 3, and 4, where these results show the effects of temperature, time, and microalgal biomass loading on carbohydrate yields, respectively. 
14 Kinetic Study of Subscritical Water Extraction of Carbohydrate from Microalgae Nannochloropsis sp.

\section{The influence of temperature of SWE on carbohydrate yield}

As shown in Figure 2, the effect of temperature on carbohydrate yields during SWE process showed that carbohydrate yield increased from $160-200{ }^{\circ} \mathrm{C}$, then rapidly decreased as the temperature increased from 200 to $320{ }^{\circ} \mathrm{C}$. The highest yield of 8.832 $\mathrm{g} / 100 \mathrm{~g}$ was achieved at $200{ }^{\circ} \mathrm{C}$, while the lowest yield of $0.816 \mathrm{~g} / 100 \mathrm{~g}$ was obtained at $320^{\circ} \mathrm{C}$. Hence, the optimum temperature of $200{ }^{\circ} \mathrm{C}$ will be used for the subsequent experiments.

The increase of process temperature resulted in a low dielectric constant, which destroyed the interactions between macromolecules (Huang et al., 2019). Furthermore, it is possible to adjust water ion products by changing temperature $(100-374$ ${ }^{\circ} \mathrm{C}$ ) and pressure (5 - $22 \mathrm{MPa}$ ) (Yang et al., 2013) to control the ability of hydrolysis, where high ion products are good for hydrolysis. Water has a maximum ion product at temperatures around $250{ }^{\circ} \mathrm{C}$, under saturated vapor pressure (Zhu et al., 2012). The water polarity changes from polar to moderate polar as the temperature increased, allowing non-polar compounds to dissolve (Zainan et al., 2019).

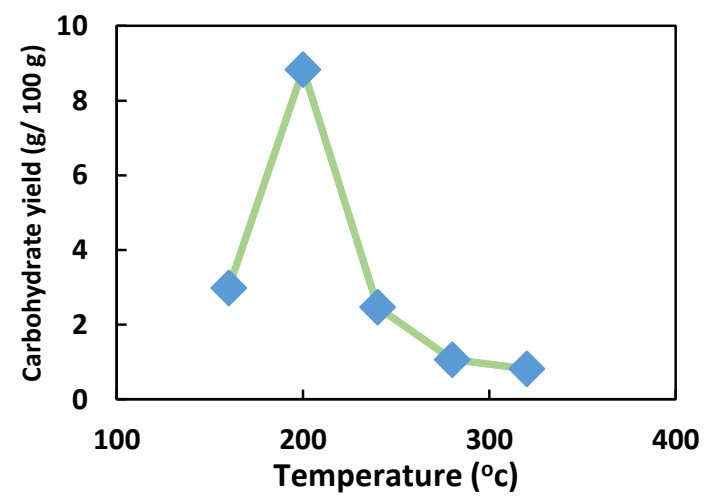

Fig. 2: Effect of different temperatures on carbohydrate yield with process conditions of $5 \mathrm{~min}$ and $5 \%(\mathrm{w} / \mathrm{v})$ microalgal biomass loading.
The result here is also in agreement with a previous study that reported the highest carbohydrate yield from microalgae Chlorella pyrenoidosa was achieved at $220^{\circ} \mathrm{C}$ (Zainan et al., 2019). The decrease of carbohydrate yield at higher temperatures might be due to the carbohydrate decomposition, while at lower temperatures, only a few carbohydrates can be separated from the microalgal cell walls.

\section{The influence of extraction time of SWE to carbohydrate yield}

Figure 3 shows the effect of extraction time on carbohydrate yield at a constant temperature of $200{ }^{\circ} \mathrm{C}$. The highest carbohydrate yield of $18.01 \mathrm{~g} / 100 \mathrm{~g}$ was achieved at $10 \mathrm{~min}$, then decreased as the time increased ( $15-25 \mathrm{~min}$ ) and the yield of $15.86 \mathrm{~g} / 100 \mathrm{~g}$ was obtained at $25 \mathrm{~min}$. Again, apparently, the carbohydrate decomposed as the time increased due to the long exposure time to heat. For a subsequent experiment, we will maintain the value of 10 min reaction time to further investigate the influence of initial microalgal concentration.

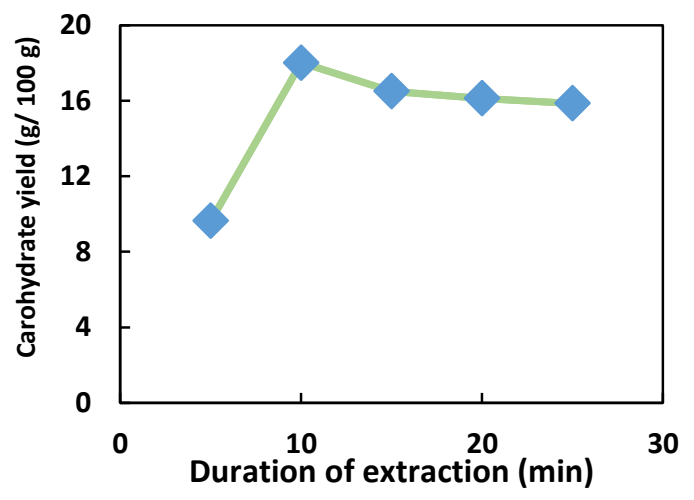

Fig. 3: Carbohydrate yield at a various duration of extraction under process conditions of $200{ }^{\circ} \mathrm{C}$ and $5 \%(w / v)$ microalgal biomass loading. 


\section{The influence of microalgal concentration on carbohydrate yield}

The effect of microalgal concentration on the carbohydrate yield is shown in Figure 4. The highest carbohydrate yield was 18.04 $\mathrm{g} / 100 \mathrm{~g}$ with $5 \%(\mathrm{w} / \mathrm{v})$ biomass loading, while the lowest carbohydrate yield was $7.9 \mathrm{~g} / 100$ $\mathrm{g}$ with $25 \%(\mathrm{w} / \mathrm{v})$ biomass loading. The result here suggested that high concentrated microalgae were generally difficult to extract. When the concentration was higher, the rigid cell walls of the microalgae tend to be harder to break (Yang et al., 2013).

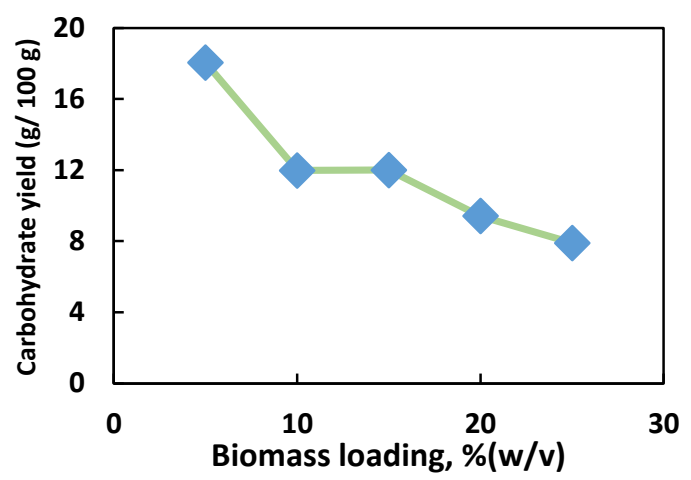

Fig. 4: Effect of microalgal concentration on carbohydrate yield with process conditions of $200^{\circ} \mathrm{C}$ and $10 \mathrm{~min}$.

\section{Development of Kinetic Model for SWE Process'}

A simplified reaction model based on a single consecutive reaction kinetics model was used in this study to describe carbohydrate production and decomposition via subcritical water reaction of microalgal biomass. The model here was adapted from Rogalinski et al. (2005), which described SWE of BSA (Bovine Serum Albumin) and Zhu et al. (2011) for subcritical water extraction bean dregs, respectively.

The resulting carbohydrate is thermally labile and it decomposes to further products, as shown in Eq. 3.
Substrate

$\stackrel{\mathrm{k}_{1}}{\rightarrow}$ Carbohydrate $\stackrel{\mathrm{k}_{2}}{\rightarrow}$ decomposition

Where $k_{1}$ is the formation rate constant of carbohydrate from microalgae substrate and $k_{2}$ is the decomposition rate constant of carbohydrate products, respectively. By assuming that each stage is an irreversible first-order reaction, the model outlined above can be described in terms of the following differential as shown in Eq. 4:

$$
\mathrm{r}_{\mathrm{s}}=\frac{-\mathrm{d}[\mathrm{s}]}{\mathrm{dt}}=\mathrm{k}_{1}[\mathrm{~s}]
$$

where $\mathbf{r}_{\mathbf{s}}$ is substrate degradation rate ( $\mathrm{g}$ $\mathrm{mL}^{-1} \mathrm{~min}^{-1}$ ), [s] is substrate concentration ( $\mathrm{g}$ $\left.\mathrm{mL}^{-1}\right), \mathrm{k}_{1}$ is the rate constant for carbohydrate formation $\left(\mathrm{min}^{-1}\right)$, and $\mathrm{t}$ is reaction time ( $\mathrm{min}$ ). The concentration of free carbohydrate is affected by two different factors: the carbohydrate production from the microalgal substrate and the decomposition to further reaction products, as illustrated in Eq. 5:

$$
\mathrm{r}_{\mathrm{c}}=\frac{\mathrm{d}[\mathrm{c}]}{\mathrm{dt}}=\mathrm{k}_{1}[\mathrm{~s}]-\mathrm{k}_{2}[\mathrm{c}]
$$

where $\mathbf{r}_{\mathbf{c}}$ is carbohydrate production rate (g $\mathrm{mL}^{-1} \mathrm{~min}^{-1}$ ), [c] is carbohydrate concentration $\left(\mathrm{g} \mathrm{mL}^{-1}\right), \mathrm{k}_{2}$ is the rate constant for carbohydrate degradation $\left(\mathrm{min}^{-1}\right)$.

$$
[\mathrm{s}]=[\mathrm{s}]_{\mathrm{O}} \exp \left(-\mathrm{k}_{1} \mathrm{t}\right)
$$

where $[\mathbf{s}]_{\mathbf{0}}$ is initial substrate concentration $\left(\mathrm{g} \mathrm{mL}^{-1}\right)$. Insertion of Eq. 6 into Eq. 5 lead to Eq. 7 :

$$
\frac{\mathrm{d}[\mathrm{c}]}{\mathrm{dt}}=\mathrm{k}_{1}[\mathrm{~s}]_{\mathrm{O}} \exp \left(-\mathrm{k}_{1} \mathrm{t}\right)-\mathrm{k}_{2}[\mathrm{c}]
$$

Rearranging Eq. 7 leads to a first order linear differential equation.

$$
\frac{\mathrm{d}[\mathrm{c}]}{\mathrm{dt}}+\mathrm{k}_{2}[\mathrm{c}]=\mathrm{k}_{1}[\mathrm{~s}]_{\mathrm{O}} \exp \left(-\mathrm{k}_{1} \mathrm{t}\right)
$$

With following boundary condition:

$\mathrm{t}=0 \rightarrow[\mathrm{c}]=0$ 
16 Kinetic Study of Subscritical Water Extraction of Carbohydrate from Microalgae Nannochloropsis $\mathrm{sp}$.

Hence, the dependence of carbohydrate concentration on extraction time is obtained by solving Eq. 8

$$
\frac{[\mathrm{c}]}{[\mathrm{s}]_{\mathrm{O}}}=\frac{\mathrm{k}_{1}}{k_{2}-k_{1}}\left(\exp \left(-\mathrm{k}_{1} \mathrm{t}\right)-\exp \left(\mathrm{k}_{2} \mathrm{t}\right)\right)
$$

Eq. 9 describes the carbohydrate yield $[\mathrm{c}] /[\mathrm{s}]_{\mathrm{o}}$ based on the initial microalgal biomass loading assuming a consecutive reaction. The final yield is expressed as $\mathrm{g}$ carbohydrate/g microalgae.

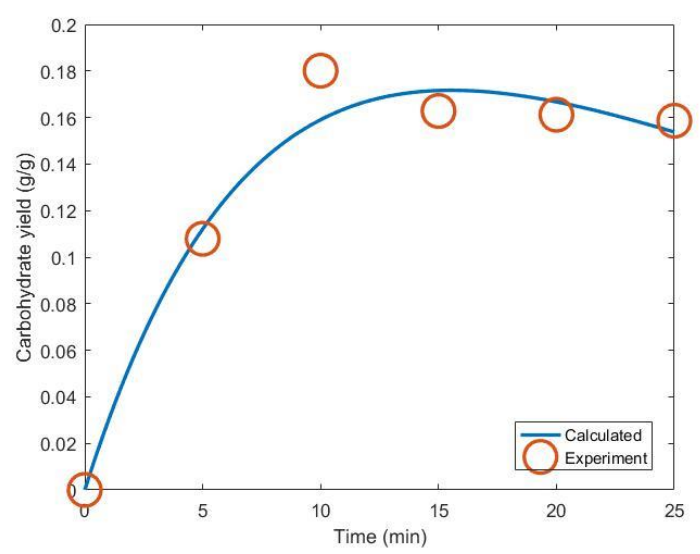

Fig. 5: Experimental data and calculated curves for carbohydrate production from SWE

The rate constants $\mathrm{k}_{1}$ and $\mathrm{k}_{2}$ can be obtained by fitting the experimental data using MATLAB software. In this experiment, the hydrolysis behaviors of carbohydrates were studied at the varying time of $5,10,15$, 20 , and $25 \mathrm{~min}$ at a temperature of $200{ }^{\circ} \mathrm{C}$. Figure 5 illustrates the course of carbohydrate production at different extraction times. The values shown by solid lines were calculated for carbohydrate concentrations. The agreement between experimental data and theoretical values could be observed. The obtained curves describe the data reasonably well. Although the simplifications described in the reaction model and the variation of the experimental data point only a fit approximation that could be achieved, the reaction model can describe at least the trends of the experimental data. The rate constants for the carbohydrate production and decomposition obtained by fitting the curve progressions to the experimental data are $\mathrm{k}_{1} 0.0320 \mathrm{~min}^{-1}$ and $\mathrm{k}_{2}$ $0.1132 \mathrm{~min}^{-1}$.

\section{CONCLUSIONS}

The influence of temperature, extraction time, and microalgal biomass loading on SWE process has been investigated using OFAT (One Factor at a time) method. The results of this study showed that SWE is a promising carbohydrate extraction method for microalgae. It is also found that all three parameters had a significant effect on the carbohydrate extraction process of microalgae. Carbohydrate yield decreases when temperature, extraction time, and microalgal biomass loading increase. The highest yield of total carbohydrate of 18.04 $\mathrm{g} / 100 \mathrm{~g}$ was obtained at $200{ }^{\circ} \mathrm{C}, 10 \mathrm{~min}$, and $5 \%(\mathrm{w} / \mathrm{v})$ microalgal biomass loading.

A simple reaction model could describe the production and decomposition of carbohydrate according to the pattern of a consecutive reaction. A good agreement between experimental data and the equations was obtained with kinetic parameters of $\mathrm{k}_{1}=0.0320 \mathrm{~min}^{-1}$ and $\mathrm{k}_{2}=$ $0.1132 \mathrm{~min}^{-1}$.

\section{ACKNOWLEDGEMENT}

This work has been supported by Universitas Gadjah Mada through a research grant of Rekognisi Tugas Akhir 2020 (Letter of assignment No. 2488/UN1.P.III/DITLIT/PT/2020). We would also like to acknowledge the Department of Chemical and Environmental, Universiti Putra Malaysia for all the support to carry out this research. 


\section{REFERENCES}

1. Al hattab, M., \& Ghaly, A. (2015). Microalgae Oil Extraction Pre-treatment Methods: Critical Review and Comparative Analysis Fundamentals of Renewable Energy and Applications. Journal of Fundamentals of Renewable Energy and Applications, 5(4). https://doi.org/10.4172/20904541.1000 172

2. Awaluddin, S. A., Thiruvenkadam, S., Izhar, S., Hiroyuki, Y., Danquah, M. K., \& Harun, R. (2016). Subcritical Water Technology for Enhanced Extraction of Biochemical Compounds from Chlorella vulgaris. BioMed Research International, 2016, $1-10$. https://doi.org/10.1155/2016/5816974

3. Chan, Y. H., Quitain, A. T., Yusup, S., Uemura, Y., \& Sasaki, M. (2017). Optimization of Hydrothermal Liquefaction of Palm Kernel Shell and Consideration of Supercritical Carbon Dioxide Mediation Effect. The Journal of Supercritical Fluids, 1-7. https://doi.org/10.1016/j.supflu.2017.06. 007

4. De Morais, M. G., Vaz, B. D. S., De Morais, E. G., \& Costa, J. A. V. (2015). Biologically Active Metabolites Synthesized by Microalgae. BioMed Research International, 2015, 1-15. https://doi.org/10.1155/2015/835761

5. Dubois, M., Gilles, K., Hamilton, J. K., Rebers, P. A., \& Smith, F. (1951). A colorimetric method for the determination of sugars. Nature, 168(4265), 167. https://doi.org/10.1038/168167a0

6. Huang, R., Cheng, J., Qiu, Y., Zhang, Z., Zhou, J., \& Cen, K. (2019). Solvent-Free Lipid Extraction from Microalgal Biomass with Subcritical Water in a Continuous Flow Reactor for Acid-Catalyzed Biodiesel Production. Fuel, 253(January), 90-94.

https://doi.org/10.1016/j.fuel.2019.05.00 4

7. Jin, M., Oh, Y., Chang, Y. K., \& Choi, M.
(2017). Optimum Utilization of Biochemical Components in Chlorella sp. KR1 via Subcritical Hydrothermal Liquefaction. Sustainable Chemistry\&Engineering, 5, 7240-7248. https://doi.org/10.1021/acssuschemeng. $7 \mathrm{~b} 01473$

8. Rogalinski, T., Herrmann, S., \& Brunner, G. (2005). Production of Amino Acids from Bovine Serum Albumin by Continuous Sub-Critical Water Hydrolysis. Journal of Supercritical Fluids, 36(1), 49-58. https://doi.org/10.1016/j.supflu.2005.03. 001

9. Shahid, A., Khan, F., Ahmad, N., Farooq, M., \& Mehmood, M. A. (2020). Microalgal Carbohydrates and Proteins: Synthesis, Extraction, Applications, and Challenges (M. A. Alam, J.-L. Xu, \& Z. Wang (eds.)). Springer Nature Singapore. https://doi.org/10.1007/978-981-150169-2

10. Tsubaki, S., Onda, A., Hiraoka, M., Fujii, S., Azuma, J. ichi, \& Wada, Y. (2017). Microwave-Assisted Water Extraction of Carbohydrates From Unutilized Biomass. In Water Extraction of Bioactive Compounds: From Plants to Drug Development. Elsevier Inc. https://doi.org/10.1016/B978-0-12809380-1.00007-3

11. Vahabisani, A., Tavakoli, O., \& Karbassi, A. R. (2015). The Influence of Acid Hydrolysis on Carbohydrate Extraction from Biomass of Microalgae (C-Vulgaris). The Influence of Acid Hydrolysis on Carbohydrate Extraction from Biomass of Microalgae (C- Vulgaris), February 2016, 2-6.

12. Yang, L., Qu, H., Mao, G., Zhao, T., Li, F., Zhu, B., Zhang, B., \& Wu, X. (2013). Optimization of Subcritical Water Extraction of Polysaccharides from Grifola Frondosa using Response Surface Methodology. Pharmacognosy Magazine, 9(34), 120-129. https://doi.org/10.4103/09731296.111262

13. Zainan, N. H., Thiruvenkadam, S., 
18 Kinetic Study of Subscritical Water Extraction of Carbohydrate from Microalgae Nannochloropsis sp.

Danquah, M. K., \& Harun, R. (2019). Biochemical Analysis and Potential Applications of Aqueous and Solid Products Generated from Subcritical Water Extraction of Microalgae Chlorella pyrenoidosa Biomass. Journal of Applied Phycology, $\quad 1-16$. https://doi.org/10.1007/s10811-01901960-0

14. Zhao, G., Chen, X., Wang, L., Zhou, S., Feng, H., Chen, W. N., \& Lau, R. (2013). Ultrasound Assisted Extraction of Carbohydrates from Microalgae as Feedstock for Yeast Fermentation. Bioresource Technology, 128, 337-344. https://doi.org/10.1016/j.biortech.2012. 10.038

15. Zhu, G., Zhu, X., Fan, Q., \& Wan, X. (2011). Kinetics of Amino Acid Production from Bean Dregs by Hydrolysis in Sub-Critical Water. Amino Acids, 40(4), 1107-1113. https://doi.org/10.1007/s00726-0100734-9

16. Zhu, G., Zhu, X., Xiao, Z., Yi, F., Ma, Y., \& $\mathrm{Ji}, \quad W$. (2012). Kinetics of Glucose Production from Cellulose by Hydrolysis in Sub-Critical Water. Advanced Materials Research, 347-353, 2672-2678. https://doi.org/10.4028/www.scientific.n et/AMR.347-353.2672 